\title{
Cure-oriented versus care-oriented attitudes in medicine
}

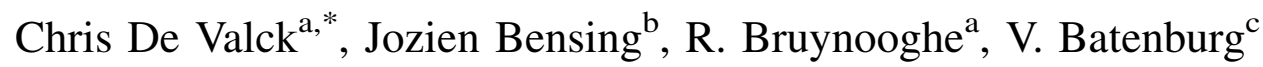 \\ ${ }^{a}$ Health Psychology Department, Faculty of Medicine, Limburgs University Centre, 3590 Diepenbeek, Belgium \\ ${ }^{\mathrm{b}}$ Netherlands Institute for Primary Health Care, Utrecht, The Netherlands \\ ${ }^{\mathrm{c}}$ Department of General Practice/Family Medicine, Faculty of Medicine, Utrecht University, Utrecht, The Netherlands
}

Received 10 October 1999; received in revised form 20 August 2000; accepted 15 October 2000

\begin{abstract}
This article focuses on the attitudinal component of patient-centredness. The literature reveals that the relationship between cure- and care-oriented attitudes remains to be clarified. The aim of this study is to gain further insight in the relationship between cure and care attitudes by questioning the bipolar unidimensional structure of the concept. By means of an empirical analysis among Belgian medical students, the cure versus care attitudes regarding the 'ideal physician' are investigated. Traits of the ideal physician are described in a bipolar rating scale reflecting cure-oriented versus care-oriented views of the medical profession. Subjects included 88 medical students of the Limburgs University Centre in Diepenbeek, Belgium. Results indicate that the Belgian sample is less care-oriented than the Dutch sample.

Further, a factor-analysis reveals two components which correspond with the instrumental (cure) and the affective dimension (care) of the medical profession. The advantages of a two-dimensional framework as a basis for the development of courses aimed at attitude development in the curriculum of a medical school are discussed. (C) 2001 Elsevier Science Ltd. All rights reserved.
\end{abstract}

Keywords: Patient-centred medicine; Cure-oriented attitude; Care-oriented attitude; Instrumental dimension; Affective dimension

\section{Introduction}

During the past years a considerable amount of the literature regarding doctor-patient communication has focused on the description of different consultation styles in the medical encounter [1-4]. The traditional and most common model is referred to as the 'doctor-centred' or 'disease-centred' approach and is characterised by an authoritarian doctor-patient relationship in which the patient fullfils a passive role and the doctor embodies medical expertise. The doctor-centred approach stems from the biomedical model of disease which defines medical care as the treatment of physical symptoms in a quantifiable way, where 'cure' is defined by objective indices. The benefit of this model is that it is scientific and evidencebased on objective medical data. An important disadvantage of this model is that it is a limited framework because it reflects an incomplete perspective on the patient's symptoms: the biomedical view loses the context of the patients symptoms as it neglects the functional, social and emotional aspects of their health.

\footnotetext{
* Corresponding author. Tel.: +32-11-268670; fax: +32-11-268700. E-mail address: chris.devalck@luc.ac.be (C. De Valck).
}

Consequently, the last decennia an expanded 'holistic' framework of health has emerged defined as the biopsychosocial model of medicine incorporating psychological and social dimensions as well as physical symptoms [5]. This approach gives room to the discussion of psychosocial topics during the consultation and views the patient as the expert of his physical state, functional status and quality of life. It implies that the doctor encourages the patient to discuss his illness experience and that the consultation is focused on both agenda's of doctor and patient. Mc Whinney [6] writes: 'the physician tries to enter the patient's world, to see the illness through the patient's eyes'. This 'patient-centred' approach in medicine is characterised by a more egalitarian doctor-patient relationship and gives equal weight to the thoughts, feelings and values of doctor and patient.

Recently, several authors [7-10] have tried to elaborate the definition of the concept of patient-centredness but despite the extensive literature there is still no universally agreed definition available. The theoretical approaches to the concept have identified the following four overlapping components of patient-centredness:

1. patient-centred attitudes or values of doctors;

2. knowledge requirements for a patient-centred approach to care; 
3. patient-centred consultation skills or behaviours;

4. the patient's role in patient-centred care.

While a lot of attention has been paid to the behavioural aspects of patient-centred medicine [10], the role of attitudes, knowledge requirements and patients behaviours remains unclear.

Within this article we specifically focus on the attitudinal component of patient-centredness. The goal of this article is to further clarify the concept of a care-oriented attitude and to determine how it is related to a cure-oriented attitude. In the past, several authors have described a wide range of attitudes that are thought to be relevant for the patientcentred approach $[11,12]$. In this line of research, the role of attitudes as determinants of the quality of the consultation behaviour is considered. For example, it is hypothesised that if a physician holds a narrow 'biomedical' view on physical symptoms this will be reflected in his consultation behaviour by means of closed questions aimed at obtaining objective medical data while physicians who hold a more 'biopsychosocial' view on physical complaints will more easily discuss psychosocial topics [2]. Likewise, biomedically oriented physicians will respond differently to patient's cues regarding his unexpressed emotions. While biomedically oriented physicians will tend to neglect these cues, physicians with a biopsychosocial view tend to encourage the patient to express his emotions by means of empathic responses resulting in the patient feeling understood [13]. In this sense the medical encounter proceeds as a dialogue instead of two parallel and largely separate monologues [14]. The link between professional attitudes and effective consultation behaviour evidently has important implications for training, if attitudes are reflected in the quality of consultation behaviour, attention should be devoted in training to attitude development and not only focus on skills training.

\subsection{The role of cure-oriented versus care-oriented attitudes in medical care}

Cure-oriented versus care-oriented attitudes in medicine have been referred to as the 'two faces of medicine', respectively, reflecting a cure or a care orientation in medicine. Bensing [3] presents an interesting theoretical framework and suggests that cure-oriented attitudes reflect the instrumental, task-oriented dimension of the medical profession while care-oriented attitudes relate to the affective dimension of the medical encounter. Cure-oriented behaviour responds to the cognitive need of the patient to reduce his uncertainty and strengthens his problem-solving coping strategies. Care-oriented behaviour responds to the affective need of the patient to reduce his anxiety thereby strengthening his emotion-focused coping.

Despite the fact that researchers agree on the importance of both in medical communication there appears to be no consensus in the literature concerning the question if these 'two faces: cure and care' are to be viewed as opponents of a continuum or as two independent components of medical care that complement each other. De Monchy et al. [15] distinguishes a continuum of professional attitudes which at the extremes are defined as 'doctor-centred' versus 'patientcentred', respectively. In an empirical study on the measurement of quality of care Bensing [16] finds that positively rated consultations hold significant more patient-centred behaviour than negatively rated consultations. However, patient-centred medicine seems to be an exception to the rule. In a comparative study of general practitioners in Belgium, Britain and The Netherlands Grol et al. [17] concluded that the majority of the doctors held doctororiented attitudes and that this behaviour correlated significantly with increased prescribing of symptomatic medication, shorter consultation time, inadequate patient records and poorer standards of care within the consultation. According to the studies of Grol et al. and Bensing, patient-centred attitudes are put forward as the ideal attitude in contrast to the doctor-centred attitude; doctor-centred attitudes and patient centred attitudes are viewed as the two opposite poles of a unidimensional continuum referred to as cure versus care, doctor-oriented versus patientoriented.

Our own experience with discussion groups with first year medical students have also revealed that medical students consider care attitudes as opposed to cure attitudes and find it very difficult to integrate both attitudes in their role as a future physician. Qualitative analysis of the discussion revealed that students fear that adopting a care attitude will make them unprofessional and vulnerable in their role as physician. These barriers to the adoption of a care attitude in medical care have contributed to what has been described as the 'dehumanisation' in medical school. It appears that students do not improve and sometimes even deteriorate in their humane attitude towards patients the further they advance in medical training [18-20]. According to the perception of students, emotional detachment is regarded as a condition that is necessary to acquire a professional attitude. This attitude is encouraged early in medical school where students are expected to stay in control of their emotions during their initial encounter with a cadaver in the dissecting room [21]. From the doctor's point of view absence of emotion leads to more efficient decision-making, on the other hand studies have indicated that this absence of emotion often results in growing 'cynicism' as students progress through medical school [22].

As long as care attitudes or patient-centred attitudes remain to be perceived by doctors as 'unprofessional' we can expect that it will be very difficult to change physicians toward more patient-centred behaviour. The adoption of care attitudes by physicians implies that they become incorporated in their role model of the professional ideal physician. As Whitehouse et al. [23] and Mc Whinney [6] put it: "patient-centredness should not be considered as a timeconsuming luxury but as sound clinical competence". Therefore, it is important that (a) care attitudes are not 
opposed to professional cure attitudes; (b) care attitudes are referred to as professional attitudes. It implies that the 'ideal physician' is viewed as a physician who is professional in the instrumental as well as in the affective components of his task.

\subsection{Research questions}

This study was undertaken in order to clarify the view medical students hold of the ideal physician. Specifically, the interrelationship between cure and care attitudes is questioned. The research questions are the following:

1. Firstly, in line with previous research $[11,15]$, we want to describe the attitudes regarding the ideal physician in a sample of Belgian medical students. By employing an existing instrument [11] we will replicate Batenburg's study in a Belgian sample and compare our findings to Batenburg's results in a Dutch sample. We expect that, since the curriculum in Belgium does not include any courses in attitude development or training in communication skills, the students to be rather cure-oriented. Also, we want to verify if male and female students differ on attitudes regarding the ideal physician.

2. Secondly, we want to explore by means of factoranalysis if the traits of the ideal physician as perceived by medical students refer to independent dimensions in medical care; specifically we want to look at the interrelationship of the 'two faces of medicine: cure and care'.

3. Finally, we want to describe the sample in terms of the new variables constructed on the basis of the factoranalytic solution. Doing so, we want to provide a new framework to describe different prototypes of the ideal physician in terms of independent dimensions in medical care.

\section{Methods}

\subsection{Subjects}

The study was carried out at the Faculty of Medicine of the Limburgs University Centre in Diepenbeek, Belgium. Subjects included 88 third year medical students of which 42 male and 46 female students. The third year is the last preclinical year in the medical curriculum in Belgium which is followed by four clinical years. At the time of the study the medical curriculum at the Limburgs University Centre did not supply an obligatory course in communication training. Subjects were tested as part of their compulsory curriculum excluding self-selection. The results of the this sample are compared with a previous study by Batenburg [11] which included a sample of 434 medical students of the Utrecht University in the Netherlands. The Dutch sample included 192 male and 242 female subjects.

\subsection{Measures}

Attitudes of medical students regarding the medical profession were measured by The Ideal Physician Questionnaire [11]. This scale consists of 18 bipolar items describing traits of the ideal physician, for example democratic opposed to hierarchical, committed versus distant, person-centred versus disease-centred. Agreement is indicated on a seven-point scale of the Likert-type. The reliability of this questionnaire, measured by Cronbach's Alpha is 0.77 which is satisfactory. Batenburg [11] investigated the convergent and construct validity of the scale. Construct validity was obtained by comparing the scores of female and male students; female students scores were more care-oriented than male students scores. Pearson correlation coefficients for testing the convergent validity varied between 0.57 and 0.90 which sustains the convergent validity of the scale. Batenburg [11] concluded that this questionnaire was useful for measuring attitudes regarding traits of the ideal physician. Batenburg [11] operationalises cure versus care attitudes as a unidimensional concept and interprets mean scores below 3.5 as a cure-oriented attitude and scores above 4.5 as a careoriented attitude. Scores between 3.5 and 4.5 are regarded as 'neutral'.

\section{Results}

In our first research question, we want to replicate Batenburg's study and describe the attitudes of medical students regarding traits of the ideal physician in a Belgian sample.

Table 1 gives an overview of the mean scores and standard deviations of the Belgian sample on the 18 original items of the Ideal Physician Scale. In order to compare our findings to the results of Batenburg, the results of Batenburg's study are implemented in Table 1 and a Student $t$-test for comparing means of independent samples was performed to test the differences between our findings and Batenburg's study. A Bonferroni test for multiple correction indicated that for a comparison of 18 mean item scores a $P$-level lower than 0.006 is to be regarded as significant.

The results indicate that in eight of the 18 items, Belgian students are more care-oriented, in four items the mean score is neutral and in five items the mean score falls in the cureoriented range of the scale. By combining the most extreme mean scores of the traits of the ideal physician, the data of our study refer to a profile of the ideal physician as someone who is open, a team-member, considerate, rational, intervening and certain.

Regarding the comparison with the Dutch sample of Batenburg's study, there appears to be a significant difference between the mean scores of Belgium and the Netherlands on nine of the 18 items; for eight of the nine items, the Dutch sample appears to be more care-oriented than the Belgian sample. This finding will be further elaborated-on in Section 4. 
Table 1

Mean scores and standard deviations on the Ideal Physician Scale of a Dutch sample $(n=434)$ and a Belgium sample $(n=88)$ of medical students $^{\mathrm{a}}$

\begin{tabular}{|c|c|c|c|}
\hline & \multicolumn{2}{|c|}{ Mean (S.D.) } & \multirow[t]{2}{*}{$P$-value } \\
\hline & Belgium & $\begin{array}{l}\text { The } \\
\text { Netherlands }\end{array}$ & \\
\hline Reticent/open & $5.7(0.98)$ & $5.3(1.43)$ & $0.006^{*}$ \\
\hline Soloist/team member & $5.3(1.22)$ & $5.3(1.58)$ & 0.880 \\
\hline Businesslike/considerate & $5.2(1.03)$ & $4.9(1.49)$ & 0.036 \\
\hline Distant/committed & $5.2(1.08)$ & $5.4(1.41)$ & 0.311 \\
\hline Hierarchical/democratic & $5.0(1.22)$ & $5.4(1.55)$ & 0.043 \\
\hline Disease-centred/person-centred & $4.8(1.10)$ & $5.4(1.44)$ & $0.000^{*}$ \\
\hline Somatic/psychosocial & $4.7(1.10)$ & $4.3(1.49)$ & 0.027 \\
\hline Scientist/care-provider & $4.6(1.18)$ & $5.2(1.50)$ & $0.001^{*}$ \\
\hline Objective/empathic & $4.2(1.22)$ & $4.7(1.60)$ & 0.009 \\
\hline Technician/confessor & $4.1(1.04)$ & $4.1(1.51)$ & 0.849 \\
\hline Analysing/integrating & $3.9(0.90)$ & $4.5(1.57)$ & $0.002^{*}$ \\
\hline Expert/general practitioner & $3.8(1.06)$ & $4.3(1.69)$ & 0.007 \\
\hline Common sense/compassionate & $3.4(1.16)$ & $4.0(1.64)$ & $0.002^{*}$ \\
\hline Logical/intuitive & $3.1(1.01)$ & $3.8(1.74)$ & $0.000^{*}$ \\
\hline Conducting/following & $3.1(1.33)$ & $3.5(1.72)$ & 0.023 \\
\hline Rational/emotional & $3.0(1.04)$ & $3.6(1.74)$ & $0.003^{*}$ \\
\hline Intervening/contemplative & $2.9(1.12)$ & $4.2(1.62)$ & $0.000^{*}$ \\
\hline Certain/doubtful & $1.8(0.86)$ & $2.9(1.86)$ & $0.000^{*}$ \\
\hline
\end{tabular}

${ }^{\mathrm{a}}$ Cure-oriented score: $<3.5$; neutral-score: $<3.5<4.5$; care-oriented score: $\geq 4.5$.

* Bonferroni test $P$-level significant at 0.006 .

A Student $t$-test for comparing means of independent samples was performed to test differences between male and female students. A Bonferroni test for multiple testing correction indicated that for a comparison of 18 mean item scores a $P$-level $<0.006$ is to be regarded as significant. Table 2 presents the mean scores and standard deviations of the male $(n=42)$ versus the female $(n=46)$ subsample.

Contrary to expectation, there are no significant differences between the ideals of the female and the male students.

Batenburg [11] questions the relevance of a unidimensional scale to measure cure versus care attitudes in medicine and suggests that separate measurement scales of humane as well as technological attitudes should be developed. This brings us to our second research question where we want to clarify the interrelationship between cure and care aspects of medical care.

Therefore, a factor-analysis (principal component analysis with oblique rotation) was performed in order to get a better understanding of the underlying dimensions of the traits of the ideal physician. On the basis of the scree-plot a three-factor solution seemed most appropriate, three factors were maintained with an eigenvalue greater than 1.5. An oblique rotation was performed because this allows the factors to correlate freely and makes it possible to explore the interrelationship of the factors found. Table 3 presents the results of a three-factor solution with oblique rotation which can be interpreted as follows.

The first factor reflects the task-oriented, instrumental dimension of the medical profession, often been referred to
Table 2

Differences in mean scores of male $(n=42)$ and female $(n=46)$ medical students on the Ideal Physician Scale

\begin{tabular}{|c|c|c|c|}
\hline & & Mean (S.D.) & $P$-value ${ }^{\mathrm{a}}$ \\
\hline Reticent/open & $\begin{array}{l}\mathrm{M} \\
\mathrm{F}\end{array}$ & $\begin{array}{l}5.74(1.06) \\
5.74(0.93)\end{array}$ & 0.996 \\
\hline Soloist/team member & $\begin{array}{l}\mathrm{M} \\
\mathrm{F}\end{array}$ & $\begin{array}{l}4.95(1.13) \\
5.57(1.24)\end{array}$ & 0.018 \\
\hline Businesslike/considerate & $\begin{array}{l}\mathrm{M} \\
\mathrm{F}\end{array}$ & $\begin{array}{l}5.19(1.06) \\
5.30(1.01)\end{array}$ & 0.608 \\
\hline Distant/committed & $\begin{array}{l}\mathrm{M} \\
\mathrm{F}\end{array}$ & $\begin{array}{l}5.31(1.16) \\
5.17(1.02)\end{array}$ & 0.560 \\
\hline Hierarchical/democratic & $\begin{array}{l}\mathrm{M} \\
\mathrm{F}\end{array}$ & $\begin{array}{l}5.19(1.15) \\
4.91(1.28)\end{array}$ & 0.290 \\
\hline Disease-centred/person-centred & $\begin{array}{l}\mathrm{M} \\
\mathrm{F}\end{array}$ & $\begin{array}{l}4.74(1.08) \\
4.78(1.13)\end{array}$ & 0.851 \\
\hline Somatic/psychosocial & $\begin{array}{l}\mathrm{M} \\
\mathrm{F}\end{array}$ & $\begin{array}{l}4.60(1.21) \\
4.74(1.00)\end{array}$ & 0.543 \\
\hline Scientist/care-provider & $\begin{array}{l}\mathrm{M} \\
\mathrm{F}\end{array}$ & $\begin{array}{l}4.55(1.04) \\
4.74(1.31)\end{array}$ & 0.452 \\
\hline Objective/empathic & $\begin{array}{l}\mathrm{M} \\
\mathrm{F}\end{array}$ & $\begin{array}{l}4.24(1.28) \\
4.22(1.19)\end{array}$ & 0.938 \\
\hline Technician/confessor & $\begin{array}{l}\mathrm{M} \\
\mathrm{F}\end{array}$ & $\begin{array}{l}4.12(0.97) \\
4.02(1.13)\end{array}$ & 0.666 \\
\hline Analysing/integrating & $\begin{array}{l}\mathrm{M} \\
\mathrm{F}\end{array}$ & $\begin{array}{l}3.83(0.80) \\
4.07(0.98)\end{array}$ & 0.225 \\
\hline Expert/general practioner & $\begin{array}{l}\mathrm{M} \\
\mathrm{F}\end{array}$ & $\begin{array}{l}3.76(1.12) \\
3.83(1.02)\end{array}$ & 0.779 \\
\hline Common sense/compassionate & $\begin{array}{l}\mathrm{M} \\
\mathrm{F}\end{array}$ & $\begin{array}{l}3.40(1.08) \\
3.43(1.24)\end{array}$ & 0.904 \\
\hline Logical/intuitive & $\begin{array}{l}\mathrm{M} \\
\mathrm{F}\end{array}$ & $\begin{array}{l}3.00(0.94) \\
3.11(1.08)\end{array}$ & 0.617 \\
\hline Conducting/following & $\begin{array}{l}\mathrm{M} \\
\mathrm{F}\end{array}$ & $\begin{array}{l}3.05(1.29) \\
3.07(1.39)\end{array}$ & 0.951 \\
\hline Rational/emotional & $\begin{array}{l}\mathrm{M} \\
\mathrm{F}\end{array}$ & $\begin{array}{l}2.98(1.00) \\
3.07(1.08)\end{array}$ & 0.691 \\
\hline Intervening/contemplative & $\begin{array}{l}\mathrm{M} \\
\mathrm{F}\end{array}$ & $\begin{array}{l}2.88(1.13) \\
2.96(1.13)\end{array}$ & 0.755 \\
\hline Certain/doubtful & $\begin{array}{l}\mathrm{M} \\
\mathrm{F}\end{array}$ & $\begin{array}{l}1.62(0.66) \\
1.93(1.00)\end{array}$ & 0.087 \\
\hline
\end{tabular}

${ }^{\mathrm{a}}$ Bonferroni test $P$-level significant at 0.006 .

as the cure dimension in medicine. Items are included with a factor loading around 0.40 on factor 1 , and low factor loadings on factors 2 and 3. Together these items form a scale with a reliability of 0.65 as determined by the alphacoefficient. The first factor has an eigenvalue of 3.00 and explains $16.7 \%$ of the total variance. There are only three items that have high factor scores on the second factor, which makes it more difficult to interpret, it can be suggested that this factor refers to scientific approach of evidencebased medicine. However, the reliability of this scale is (0.46) so we will exclude these items from our further analysis. The third factor denotes the affective dimension 
Table 3

Factor analysis on attitudes regarding traits of the ideal physician

\begin{tabular}{|c|c|c|c|c|c|}
\hline \multicolumn{2}{|c|}{ Factor 1: cure (task-oriented dimension) } & \multicolumn{2}{|c|}{ Factor 2: evidence based medicine } & \multicolumn{2}{|c|}{ Factor 3: care (affective dimension) } \\
\hline Businesslike/considerate & 0.469 & Logical/intuitive & 0.609 & Distant/committed & -0.559 \\
\hline Somatic/psychosocial & 0.550 & Intervening/contemplative & 0.616 & Objective/empathic & -0.604 \\
\hline Technician/confessor & 0.590 & Certain/doubtful & 0.627 & Rational/emotional & -0.689 \\
\hline Expert/general practitioner & 0.422 & & & Common sense/compassionate & -0.655 \\
\hline Scientist/care-provider & 0.624 & & & & \\
\hline Soloist/team member & 0.506 & & & & \\
\hline Analysing/integrating & 0.396 & & & & \\
\hline Disease-centred/person-centred & 0.677 & & & & \\
\hline Alpha & 0.65 & & 0.46 & & 0.60 \\
\hline Variance $(\%)^{\mathrm{a}}$ & 16.7 & & 12.6 & & 9.4 \\
\hline Eigenvalue & 3.00 & & 2.27 & & 1.69 \\
\hline
\end{tabular}

${ }^{\mathrm{a}}$ Total variance explained $=38.69 \%$.

of the medical encounter, better known as the care dimension in medicine. This factor is represented by four items, taken together the reliability of this scale is 0.60 . The third factor has an eigenvalue of 1.69 and explains $9.4 \%$ of the total variance. Three other items do not load on any of the three factors, these items will also be excluded (hierarchical/ democratic; conducting/following and reticent/open). This leaves us with 12 items of the Ideal Physician Scale, on which a forced two factor solution was repeated to confirm the two hypothesised dimensions. Table 4 presents the results of this forced two-factor solution which confirms the two subscales representing the two faces of medicine: cure and care. The Pearson correlation coefficient between these two scales calculated on the basis of the factor-scores is $0.191(P=0.077, \mathrm{~ns})$, which means that the cure and care dimension of medical care refer to independent dimensions.

Consequently, The ideal physician proves to be a valuable instrument to measure attitudes towards the cure or taskoriented dimension on the one hand and attitudes towards the care or affective dimension on the other hand which brings us to our last research question.

Table 4

Forced two factor solution on attitudes regarding traits of the ideal physician

\begin{tabular}{lclc}
\hline $\begin{array}{l}\text { Factor 1: cure task oriented } \\
\text { dimension }\end{array}$ & \multicolumn{3}{l}{$\begin{array}{l}\text { Factor 2: care affective } \\
\text { dimension }\end{array}$} \\
\hline Businesslike/considerate & 0.515 & Distant/committed & 0.563 \\
Somatic/psychosocial & 0.566 & Objective/empathic & 0.580 \\
Technician/confessor & 0.560 & Rational/emotional & 0.802 \\
Expert/general practitioner & 0.410 & Common sense/ & 0.721 \\
& & compassionate & \\
Scientist/care-provider & 0.605 & & \\
Soloist/team member & 0.512 & & 0.60 \\
Analysing/integrating & 0.368 & & 13.4 \\
Disease-centred/person-centred & 0.686 & & 1.60 \\
Alpha & 0.65 & & \\
Variance $(\%)$ & 22.33 & & \\
Eigenvalue & 2.6 & & \\
\hline
\end{tabular}

${ }^{\mathrm{a}}$ Total variance explained $=35.74 \%$.
Table 5

Frequency distribution of the combined scores of attitudes regarding the instrumental and affective dimension of the medical profession

\begin{tabular}{llll}
\hline \multicolumn{4}{l}{ Affective dimension } \\
\cline { 2 - 4 } & $<4.5$ & $\geq 4.5$ & Total \\
\hline Instrumental dimension & & & \\
$\quad<4.5$ & $28 / 87(32 \%)$ & $15 / 87(17 \%)$ & $43 / 87(49 \%)$ \\
$\leq 4.5$ & $23 / 87(27 \%)$ & $21 / 87(24 \%)$ & $44 / 87(51 \%)$ \\
Total & $51 / 87(59 \%)$ & $36 / 87(41 \%)$ & $87 / 87(100 \%)$ \\
\hline
\end{tabular}

In answer to our third research question this means that the attitudes regarding the profile of the Ideal Physician of each individual may be regarded as a combination of two separate scores. Table 5 gives the frequency distribution of the combined scores of the Belgian sample. A cut-off score of 4.5 was maintained in accordance with Batenburg [11] to distinguish between high and low scores in, respectively, the instrumental, task-oriented and the affective dimension of the medical profession.

Fig. 1 presents the results of the Belgian sample as a function of the combined score of attitudes towards the instrumental (cure) and attitudes towards the affective dimension (care) of the medical profession.

These data present an interesting perspective to describe different prototypes of the ideal physician. The two poles of the instrumental dimension can be labelled biomedical versus biopsychosocial reflecting the content of the task dimension of the medical profession. The two extremes of the relational, affective dimension can be labelled personal detachment versus empathic reflecting the 'connectedness' in the doctor-patient relationship. Subjects who have high scores on the instrumental as well as on the affective dimension, $24 \%$ of the Belgian sample, hold positive attitudes towards the two faces of medicine and are cure and care oriented. They can be characterised as holding a holistic biopsychosocial view on disease and approve an empathic doctor-patient relationship. Subjects with a high score on the instrumental dimension and a low score on the affective 


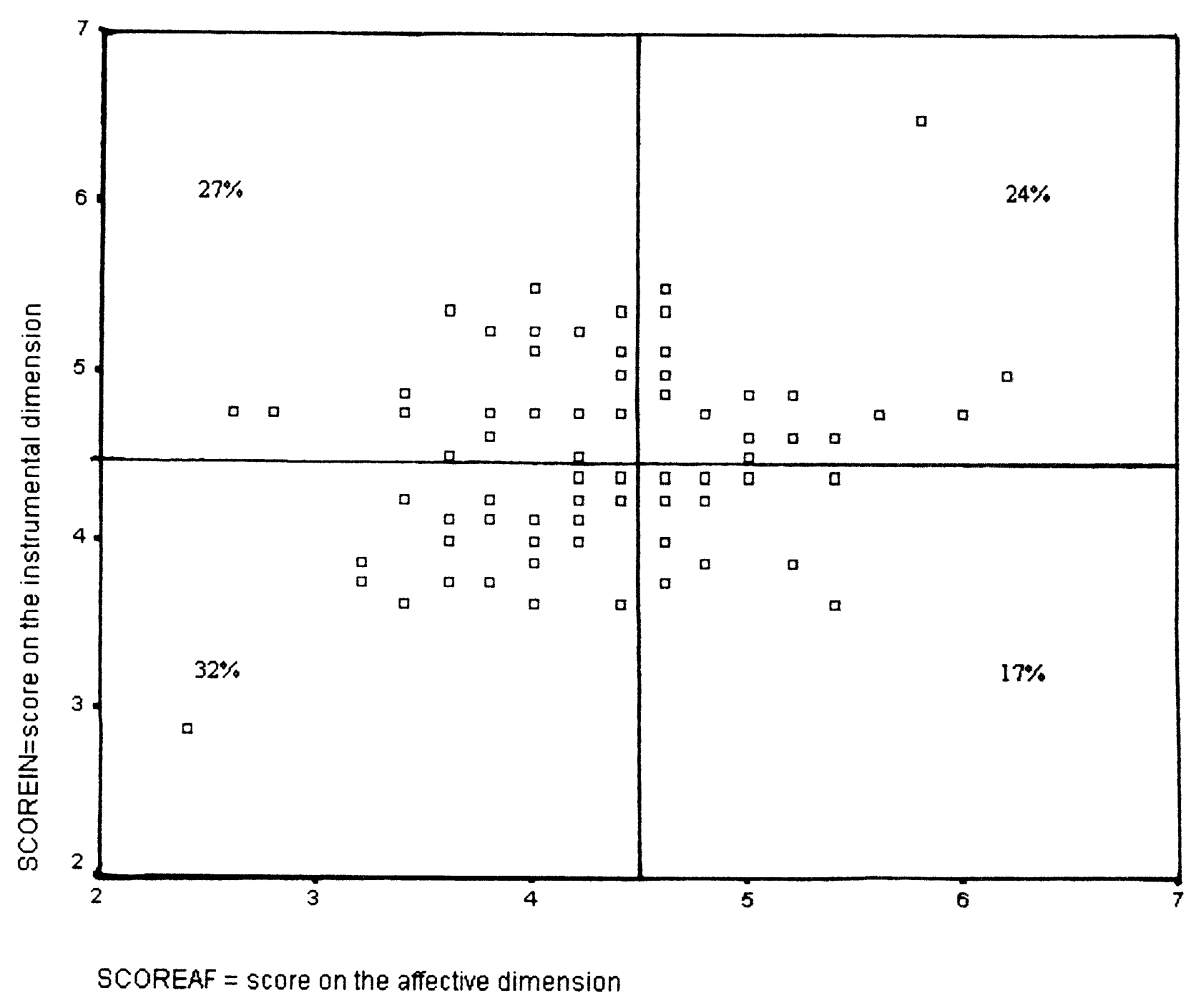

Fig. 1. Combined scores of cure (score IN) and care (score AF) attitudes regarding the ideal physician.

dimension, $27 \%$ of the Belgian sample, can be regarded as subjects that hold a positive attitude towards a biopsychosocial perspective but at the same time hold beliefs that approve emotional detachment in the doctor-patient relationship. Subjects with a low score on the instrumental dimension and a high score on the affective dimension, $17 \%$ of the above Belgian sample hold a narrow biomedical view but hold a more egalitarian view regarding the doctor-patient relationship. Subjects with low scores on both dimensions, $32 \%$ of the Belgian sample, can be regarded as holding a narrow biomedical view in combination with an authoritarian doctor-patient relationship, representing the traditional authoritarian biomedically oriented physician.

\section{Discussion and practice implications}

This study was undertaken to gain insight in the attitudes medical students hold regarding the ideal physician. Broadly speaking two attitudes have been described in the literature: cure- and care-oriented attitudes. These attitudes have long been regarded as two opposite poles of a unidimensional structure. Subjects were classified on a continuum ranging from doctor- to patient-centred and from cure- to careoriented. Due to the evolution towards a biopsychosocial perspective in medicine [5] the 'ideal physician' was more and more modelled as someone who is patient-centred and care-oriented [11,12]. In this study, we questioned the relevance of a unidimensional concept of cure and care attitudes by means of an empirical analysis among 88 Belgian medical students.

First, cure versus care attitudes were measured by means of the Ideal Physician Questionnaire, an existing scale developed and validated by Batenburg [11], which makes it possible to interpret our data in the light of previous research. Comparing our results with the findings of Batenburg [11] we may conclude the following.

First, there appears to be a significant difference between the mean scores of The Belgian sample and the Dutch sample on nine of the 18 original items. Inspection of the items reveals that Dutch students are more person-centred, more care-provider, more integrating, more contemplative, more compassionate, intuitive and emotional than Belgian students. Belgian students on the other hand are more open than Dutch students. The relevance of these differences has to be interpreted with caution because in five of the nine items the scores are still within the same score range (reticent 5.7 versus 5.3; disease-centred 4.8 versus 5.4; scientist 4.6 versus 5.2 - all within the caring range; and analysing 3.9 versus 4.5 ; and expert 3.8 versus 4.3 - within the neutral range). The differences on the remaining four items carry more meaning because they cross ranges, but the differences are between cure-oriented and neutral scores. The Belgium scores fall within the cure-oriented range while the Dutch scores fall within the neutral range. Taken these 
remarks into account the following considerations can be made about the found differences:

1. The fact that the Dutch sample is more care-oriented than the Belgian sample can be seen as the result of several communication skills courses that are part of the curriculum in the Dutch Medical School but at the time of the study were absent in the Belgian Medical School.

2. The Dutch sample consisted of a cross-sectional sample incorporating junior as well as senior medical students while the Belgian sample consists of a sample of students in the preclinical phase of education. It is known from other studies that the phase of education has an important influence on the attitudes regarding the medical profession. While dehumanisation has been described as an important negative phenomenon in the attitude development during medical school, it could also be possible that effective contact with patients in the clinical phase strengthens the care-attitude when these are combined with communication courses as is the fact in the Dutch Medical School. Therefore, it would be interesting to verify by means of a longitudinal study in which direction the attitudes of the Belgian students would develop in the clinical phase of their curriculum. It is a limitation of this study that these data are not available.

3. A third possible explanation is that cultural differences account for the more care-oriented attitude in the Dutch sample. There are important differences between the health care system of Belgium and The Netherlands. In Belgium a fee-for-service system is used whereas in the Netherlands there is a capitation system. In a comparative study of attitudes among general practitioners in Belgium, The Netherlands and Britain, Grol et al. [17] also found that the Dutch sample was more careoriented than the Belgian sample. Grol points to the fact that attitudes are a reflection of dominant cultural norms, in this sense we could argue that our Belgian sample is more cure-oriented because the paternalistic doctor-patient relationship is regarded as the norm. In the Netherlands doctors give more autonomy and selfresponsibility to their patients than in other countries. Of course, we have to be cautious with this explanation since our sample consisted of third year medical students and it remains questionable in how far they are influenced by cultural norms.

Contrary to Batenburg [11] our data reveal no gender differences while in Batenburg's study, female students were more care-oriented than male students.

Besides replicating Batenburg's study in a Belgian sample we wanted to explore the relationship between cure and care attitudes to gain further insight in the interrelationship between the basic dimensions of the medical profession. A factoranalysis on the data revealed a three-factor solution of which two factors correspond with the instrumental and the affective dimension of the medical profession. A forced two factor solution further confirmed the hypothesised dimensions of the ideal physician. The correlation between these two dimensions is 0.191 (ns). This implies that we have reasonable arguments to propose a two-dimensional instead of a unidimensional concept of attitudes regarding traits of the ideal physician.

A two-dimensional concept has two important advantages in comparison with a unidimensional concept. First of all, it makes it possible to describe different profiles or prototypes of the ideal physician based upon the combination of scores in the affective and the instrumental domain of medical care. The poles of the instrumental dimension can be labelled biomedical versus biopsychosocial reflecting the content of the task dimension of the medical profession. The poles of the affective dimension can be labelled personal detachment versus empathic reflecting the interdependence or connectedness in the doctor-patient relation. As such it provides an interesting framework to describe differences in attitudes regarding the medical profession. Interestingly, these results are in line with the framework proposed by Bensing [7] who described a biodimensional structure of the patient-centredness concept. Besides the content of the consultation Bensing [7] proposes the control over the consultation as the two basic dimensions of the medical encounter and also suggests that these dimensions should be conceived as relatively independent from each other. Secondly, a unidimensional concept of cure versus care is an important barrier for the development of more care-oriented attitudes because it implies that developing more care-oriented attitudes decreases the cure-oriented attitude. In this sense it corresponds with what physicians and medical students are afraid of: a patient-centred attitude is in conflict with a cureoriented attitude and will make them feel unprofessional. Our two-dimensional solution suggests that care and cure attitudes complement each other rather than that they compete each other. This provides a more 'safe' framework for courses aimed at attitude development in the medical curriculum. It incorporates a care attitude besides the cure attitude as sound clinical competence as was earlier suggested by Whitehouse et al. [23]. Thereby special attention in training should be devoted to the teaching of cure and care attitudes which are compatible. For example, for history taking and diagnostic reasoning students are taught to ask the patient closed questions which only require a yes-no answer. This type of questioning is not in line with a patient-centred approach that points to the importance of open questions. Communication training should focus on the integration of a humane attitude while maintaining professional competence in diagnostic reasoning and decision-making. Levinson and Roter [24] have demonstrated that communication between physicians and patients is associated with underlying physician attitudes. Patient of physicians with more positive attitudes have more psychosocial discussions in visits than do patients with less positive attitudes.

On the basis of these findings we may conclude that a two-dimensional framework incorporating the cure and care 
dimension in medicine offers an interesting perspective to bridge the gap between actual behaviour and the ideal model regarding the quality of communication in the medical profession.

\section{Acknowledgements}

K.P. van de Woestijne provided valuable suggestions during the preparation of the manuscript.

\section{References}

[1] Roter DL, Hall JA. Doctors talking with patients. Patients talking with doctors. London: Auburn House, 1992.

[2] Verhaak PFM. Detection of psychological complaints by general practitioners. Med Care 1988;26:1009-20.

[3] Bensing JM. Impliciete theoriën in onderzoek naar arts - patiënt communicatie. Huisarts en Wetenschap 1991;34(7):311-9.

[4] Butow PN, Dunn SM, Tattersall MHN, Jones QJ. Computer-based interaction analysis of the cancer consultation. $\mathrm{Br} \mathrm{J}$ Cancer 1995; 71:1115-21.

[5] Engel GL. The need for a new medical model: a challenge for biomedicine. Science 1977;196:129-35.

[6] Mc Whinney IR. Patient-centered and doctor-centered models of clinical decision making. In: Shelden M, Brook J, Rector A, editors. Decision making in general practice. London: Stockton, 1985.

[7] Bensing J. Bridging the gap. The separate worlds of evidence-based medicine and patient-centered medicine. Patient Educ Counsel 2000;39:17-25.

[8] Mead N, Bower P. Measuring patient-centredness: a comparison of three observation-based instruments. Patient Educ Counsel 2000;39:71-80.

[9] Putman S, Lipkin M. The Patient-centered interview: research support. In: Lipkin M, Putnam SM, Lazare A, editors. The Medical Interview. New York: Springer, 1995. p. 530-7.
[10] Stewart M, Brown J, Weston W, Mc Whinney I, Mc William C, Freeman T. Patient-centred medicine. Transforming the clinical method. Thousand Oaks: Sage, 1995.

[11] Batenburg V. Medical students' Attitudes. Attitude development in a Medical School. Dissertation. The Netherlands: Medical School, Utrecht University, 1997.

[12] De Monchy C. Professional attitudes of doctors and medical teaching. Med Teacher 1992;14:327-31.

[13] Suchman AL, Markakis K, Beckman HB, Frankel R. A model of empathic communication in the medical interview. JAMA 1997;277:678-82.

[14] Mishler EG. The discourse of medicine: dialectics of medical interviews. Norwood (NJ): Ablex, 1984.

[15] De Monchy C, Richardson R, Brown RA, Harden RM. Measuring attitudes of doctors: the doctor-patient (DP) rating. Med Educ 1988;22:231-9.

[16] Bensing JM. Doctor-patient communication and the quality of care. Soc Sci Med 1991;32:1301-10.

[17] Grol R, de Maeseneer J, Whitfield MM. Disease-centred versus patient-centred attitudes: comparison of general practitioners in Belgium, Britain and The Netherlands. Fam Pract 1990;7:100.

[18] Rezler AG, Haken J. Affect and research in medical education. Med Educ 1984;18:331-8.

[19] Wolf TM, Almen TK, Faucett JM, Randall HM, Franklin FA. Psychosocial changes during the first year of medical school. Med Educ 1991;174-181.

[20] Brock CD, Johnson AH, Durand RP, Levine JH, Downey DB. The erosion of empathy in medical education: a comparison of freshman and junior medical student responses to the Barett-Lennard relationship inventory. J Balint Soc 1992;8-9.

[21] Horne DJ, Tiller JWG, Eizenberg N, Tashevska M, Biddle N. Reactions of first year medical students to their initial encounter with a cadaver in the dissecting room. Acad Med 1990;65:645-6.

[22] Gordon J, Mesh I. Values of medical students at different levels of training. J Educ Psychol 1962;53:48-51.

[23] Whitehouse C, Morris P, Marks B. The role of actors in teaching communication. Med Educ 1984;18:262-8.

[24] Levinson W, Roter D. Physicians' psychosocial beliefs correlate with their patient communication skills. J Gen Int Med 1995;10:375-9. 